\title{
Characterization and Aliphatic Aldehyde Content of Particulates in Chinese Incense Smoke
}

\author{
J. M. Lin, C. S. Tang \\ Division of Environmental Health, College of Public Health, National Taiwan \\ University, Room 1451, No. 1, Jen-Al Road, 1st Sec., Taipei, Taiwan, \\ Republic of China
}

Received: 16 January 1994/Accepted: 1 May 1994

It is known that both wood dust and formaldehyde can impair mucociliary clearance (Black et al, 1974). Epidemiological studies have correlated wood dust and formaldehyde with nasal cancer (Whi tehead, 1982; National Research. Council, 1981). Wood dust as a carrier of formaldehyde enhances the hazardous properties of formaldehyde when the wood dust is intercepted and dissolved in water in the nasal cavity (Stumph et al, 1986).

Burning Chinese incense for worshipping deities is a daily routine for most Chinese. Burning incense might also generate aerosols and formaldehyde because most materials produce aldehydes and ketones during combustion (Gotze and Harke, 1989). Te characterize the aerosol and its alphatic aldehyde content in this study.

\section{MATERIALS AND METHODS}

Four types of stick incense containing sandalwood powder were burned in a chamber. The chamber $(68 \times 48 \times 44 \mathrm{~cm})$ was constructed from polypropylene. A stream of purified air was distributed into the chamber through a tube $(680 \mathrm{~mm}$ long diameter $5 \mathrm{~mm}$ )with 13 holes (diameter $5 \mathrm{~mm}$ ). The exhaust air was discharged into a hood. A pump(model 224-30, SKC, USA) was used to maintain the dynamic equilibrium between the inlet and the outlet flow rates. A F low-temperature-humidity control system (HCS-301, MNR, USA) was used to control the humidity in the chamber. A dew point hygrometer (model 91, YSI, USA) was utilized to monitor the relative humidity inside the chamber.

A stick of incense was ignited by a nickle-chrome wire regulated by a transformer after the burning chamber had been purged by purified air with a flow rate of $5 \mathrm{~L} / \mathrm{min}$ for $30 \mathrm{~min}$.

Correspondence to: J. M. Lin 
The smoke generated from burning Chinese incense was sampled by a Mini Anderson multi-stage cascade impactor (Anderson personnel particle sizing sampler, Anderson, USA) in parallel with a $37 \mathrm{~mm}$ cellulose-ester filter (SKC, USA) in a two-piece cassette $(37 \mathrm{~mm}$, SKC, USA). The flow rate was $1.4 \mathrm{~L} / \mathrm{min}$ for the Anderson sampler and $0.5 \mathrm{~L} / \mathrm{min}$ for the filter. The sampling time varied from $2 \mathrm{~min}$ to 10 min depending on the concentration of aerosol generated.

After sampling was completed, the sample collected by the Anderson sampler was conditioned for $24 \mathrm{hr}$ in an electronic desiccator (ED100 , Toyo Living, Japan) with $50 \%$ relative humidity and weighed by a balance (M3P-000V001, Sartorius, Germany). Subsequently, each stage was immersed in acetonitrile ( $5 \mathrm{~mL}, \mathrm{BDH}$ 152856K, England) for $30 \mathrm{~min}$ and the extract was eluted through a 2,4-dinitrophenyl hydrazine-coated Sep-Pak DNPH-silica cartridge (part No. 37500, Millipore). The eluent was collected and then brought up to $5 \mathrm{~mL}$ by the addition of acetonitrile. 4-fluorobenzonitrile (Fluka, 46680, Switzerland) in acetonitrile at a concentration of 0.134 $\mathrm{g} / 10 \mathrm{~mL}$ which served as an internal standard was added to the eluent. Aldehyde standard solution kit (TK-151) was provided by All tech.

A high performance liquid chromatograph (Model 590, Faters, USA) equipped with an UV absorbance detector (UV $254 \mathrm{~nm}$, series 400 , Haters) was used to determine the 2,4-DNPH derivatives of the aliphatic aldehydes in the extract from aerosol. The injection volume was $10 \mu \mathrm{L}$. The column was Nova-Pak C18(150 mm $\times 3.9 \mathrm{~mm})$ and the flow rate of the solvent system (acetonitrile/ $\mathrm{H}_{2} 0 ; 60 / 40$ $\mathrm{V} / \mathrm{V}$ ) was $1.0 \mathrm{~mL} / \mathrm{min}$.

The particulates retained in each cellulose-ester filter were counted and sized. About one-eighth of a filter was cut, mounted on a slide and treated with an acetone vaporizer(Vap-200, BGI, USA) to become transparent. The counting and sizing of the particulates was conducted using a microscope (Alphaphot-2 YSI, Nikon, Japan) interlinked with an image analysis system (PC-meter, Hanka, Taiwan). In addition, the morphology of aerosols was examined by a scanning electron microscope (JSM-300TA, JEOL, Japan).

The above-mentioned methods were also employed for sampling and analyzing field samples which were collected from a site located $150 \mathrm{~cm}$ above ground level and $10 \mathrm{~cm}$ away from an incense holder in a courtyard of Lungshan Temple, a Chinese temple in Taipei.

\section{RESULTS AND DISCUSSION}

Table 1 shows the results obtained by filtration and microscopic examination with an image analysis system. The diameter of the 
particles from various kinds of Chinese incense smoke ranged from $0.36 \mu \mathrm{m}$ to $2.88 \mu \mathrm{m}$, and the areas ranged from $0.103 \mu \mathrm{m}^{2}$ to $6.492 \mu \mathrm{m}^{2}$. Both the size distribution and the numerical concentration depended on the conditions under which the incense was burned. The concentration of particulates from burning Chinese incense increased with the relative humidity in the burning chamber. The maximum diameter and the maximum area of particles from all kinds of Chinese incense except the Taiwan Yellow incense also increased with the relative humidity. The increase in particle size in high relative humidity is probably due to the coagulation of particles. However, the exception which occurred in the case of Taiwan Yellow incense implies that the hydroscopic properties of particulates may vary with the type of Chinese incense. It is likely that the hydroscopic particulates in high concentrations easily coagulate.

Table 1. Microscopic determination of concentration and size distribution of particulates from incense smoke

\begin{tabular}{|c|c|c|c|c|c|c|}
\hline \multirow{2}{*}{$\begin{array}{l}\text { Type of } \\
\text { stick } \\
\text { incense }\end{array}$} & \multirow{2}{*}{$\begin{array}{l}\text { R.H. }(\%) \& \\
\text { Temp. }\left({ }^{\circ} \mathrm{C}\right) *\end{array}$} & \multirow{2}{*}{$\begin{array}{c}\text { Conc. } \\
\left(\text { No. } / \mathrm{cm}^{3}\right)\end{array}$} & \multicolumn{2}{|c|}{ Surface area $\left(\mu \mathbb{\mathbb { m }}^{2}\right)$} & \multicolumn{2}{|c|}{ Diameter $(\mu \mathrm{m})$} \\
\hline & & & Maximum & Minimum & Maximum & Minimum \\
\hline Taiwan & $50.5 ; 23.8$ & 2617.9 & 2.267 & 0.103 & 1.70 & 0.36 \\
\hline \multirow[t]{2}{*}{ Yellow } & $61.0 ; 22.0$ & 3226.0 & 1.752 & 0.103 & 1.49 & 0.36 \\
\hline & $85.0 ; 22.0$ & 4125.8 & 1.340 & 0.103 & 1.31 & 0.36 \\
\hline Mainland & $46.1 ; 20.0$ & 2693.8 & 1.453 & 0.104 & 1.36 & 0.36 \\
\hline \multirow{2}{*}{ Black } & $63.0 ; 17.0$ & 2975.8 & 2.905 & 0.104 & 1.92 & 0.36 \\
\hline & $87.8 ; 20.5$ & 4395.4 & 4.046 & 0.104 & 2.27 & 0.36 \\
\hline Taiwan & $50.0 ; 22.0$ & 1512.0 & 1.349 & 0.135 & 1.31 & 0.41 \\
\hline \multirow[t]{2}{*}{ Black } & $63.2 ; 24.0$ & 2526.4 & 1.958 & 0.103 & 1.58 & 0.36 \\
\hline & $83.0 ; 19.0$ & 3122.5 & 2.081 & 0.104 & 1.63 & 0.36 \\
\hline Japan & $45.7 ; 27.0$ & 1583.0 & 1.134 & 0.103 & 1.20 & 0.36 \\
\hline \multirow[t]{2}{*}{ White } & $65.0 ; 23.0$ & 2742.1 & 1.958 & 0.103 & 1.58 & 0.36 \\
\hline & $78.5 ; 24.5$ & 3232.8 & 6.492 & 0.103 & 2.88 & 0.36 \\
\hline $\begin{array}{l}\text { Field } \\
\text { sample** }\end{array}$ & $\begin{array}{l}41.3-46.3 \\
20.4-23.0\end{array}$ & 714.6 & 2.179 & 0.104 & 1.67 & 0.36 \\
\hline
\end{tabular}

Table 2 gives the results of particle size distribution by cascade impactor (Mini Anderson Sampler). The aerodynamic diameter of most particulates generated from burning the stick incenses in the chamber with controlled humidity was smaller than $0.65 \mu \mathrm{m}$. The mass medium aerodynamic diameter (MMAD) for particulates from each kind of incense was not determined, because it was found that when the plot of size distribution was drawn on log-probability paper, the size distribution of particles did not fit a log-normal distribution. 


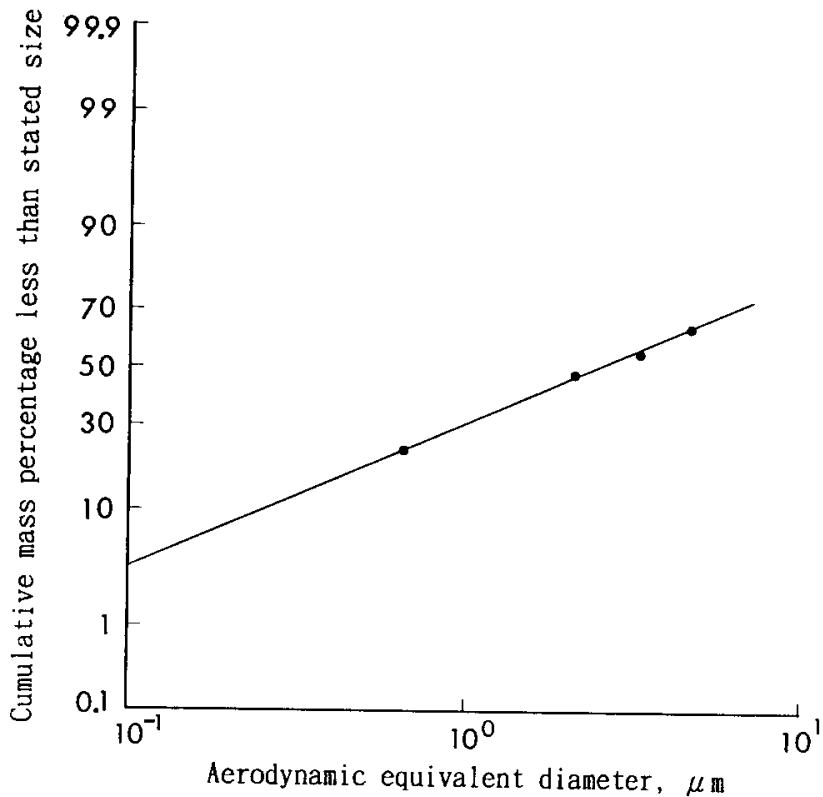

Figure 1. Plot of cumulative mass distribution of particulates collected in a Chinese temple. (MMAD $=2.5 \mu \mathrm{m} ; \mathrm{GSD}=6.6$ )

Table 2. Gravimetric determination of mass cumulative percent of particulate collected from incense smoke by Anderson samplers

\begin{tabular}{|c|c|c|c|c|c|c|c|}
\hline \multirow{2}{*}{$\begin{array}{l}\text { Type of } \\
\text { stick } \\
\text { incense }\end{array}$} & \multirow[t]{2}{*}{$\begin{array}{l}\text { R.H.(\%) \& } \\
\text { Temp. }\left({ }^{\circ} \mathrm{C}\right) *\end{array}$} & \multirow[t]{2}{*}{$\begin{array}{l}\text { Sample } \\
\text { number }\end{array}$} & \multicolumn{4}{|c|}{$\begin{array}{c}\text { Mass cumulative percentage of } \\
\text { particulates with size less } \\
\text { than effective cut size }\end{array}$} & \multirow{2}{*}{$\begin{array}{l}\text { Mass } \\
\text { conc. } \\
\mathrm{mg} / \mathbb{R}^{3} \\
\end{array}$} \\
\hline & & & $4.7 \mu \mathrm{m}$ & $3.3 \mu \mathrm{m}$ & $2.1 \mu \mathrm{m}$ & $0.65 \mu \mathrm{m}$ & \\
\hline \multirow[t]{3}{*}{$\begin{array}{l}\text { Taiwan } \\
\text { Yellow }\end{array}$} & $\begin{array}{l}45.5-50.0 \% ; \\
230-28.0^{\circ} \mathrm{C}\end{array}$ & 2 & 99.8 & 99.5 & 98.8 & 88.2 & \\
\hline & $\begin{array}{l}58.0-60.0 \% \\
22.0-25.0^{\circ} \mathrm{C}\end{array}$ & 2 & 93.4 & 92.8 & 92.6 & 79.8 & 51.4 \\
\hline & $\begin{array}{l}81.0-82.0 \% \\
21^{\circ} \mathrm{C}\end{array}$ & 2 & 98.7 & 98.7 & 98.3 & 73.4 & 59.6 \\
\hline \multirow[t]{3}{*}{$\begin{array}{l}\text { Taiwan } \\
\text { Black }\end{array}$} & $\begin{array}{l}48.0-52.0 \% ; \\
22.0^{\circ} \mathrm{C}\end{array}$ & 1 & 99.6 & 99.6 & 99.6 & 43.6 & 39.3 \\
\hline & $\begin{array}{l}60.5-65.8 \% ; \\
24.0^{\circ} \mathrm{C}\end{array}$ & 1 & 98.6 & 98.6 & 98.3 & 98.3 & 60.9 \\
\hline & $\begin{array}{l}82.4-83.6 \% ; \\
19.0^{\circ} \mathrm{C}\end{array}$ & 1 & 98.7 & 98.5 & 98.0 & 94.8 & 97.8 \\
\hline \multirow[t]{3}{*}{$\begin{array}{l}\text { Japan } \\
\text { Whi te }\end{array}$} & $\begin{array}{l}48.0-50.0 \% ; \\
25.0^{\circ} \mathrm{C}\end{array}$ & 1 & 100.0 & 95.8 & 94.3 & 71.5 & 48.4 \\
\hline & $\begin{array}{l}57.5-62.5 \% ; \\
22.0^{\circ} \mathrm{C}\end{array}$ & 1 & 98.1 & 92.3 & 92.3 & 91.4 & 47.8 \\
\hline & $\begin{array}{l}78.0-80.0 \% \\
26.0^{\circ} \mathrm{C}\end{array}$ & 1 & 98.3 & 97.1 & 97.1 & 67.4 & 39.6 \\
\hline $\begin{array}{l}\text { Field } \\
\text { sample** }\end{array}$ & $\begin{array}{l}41.3-46.3 \% ; \\
20.4-23.0^{\circ} \mathrm{C} \\
\end{array}$ & 1 & 64.0 & 55.1 & 47.5 & 22.9 & 3.2 \\
\hline
\end{tabular}




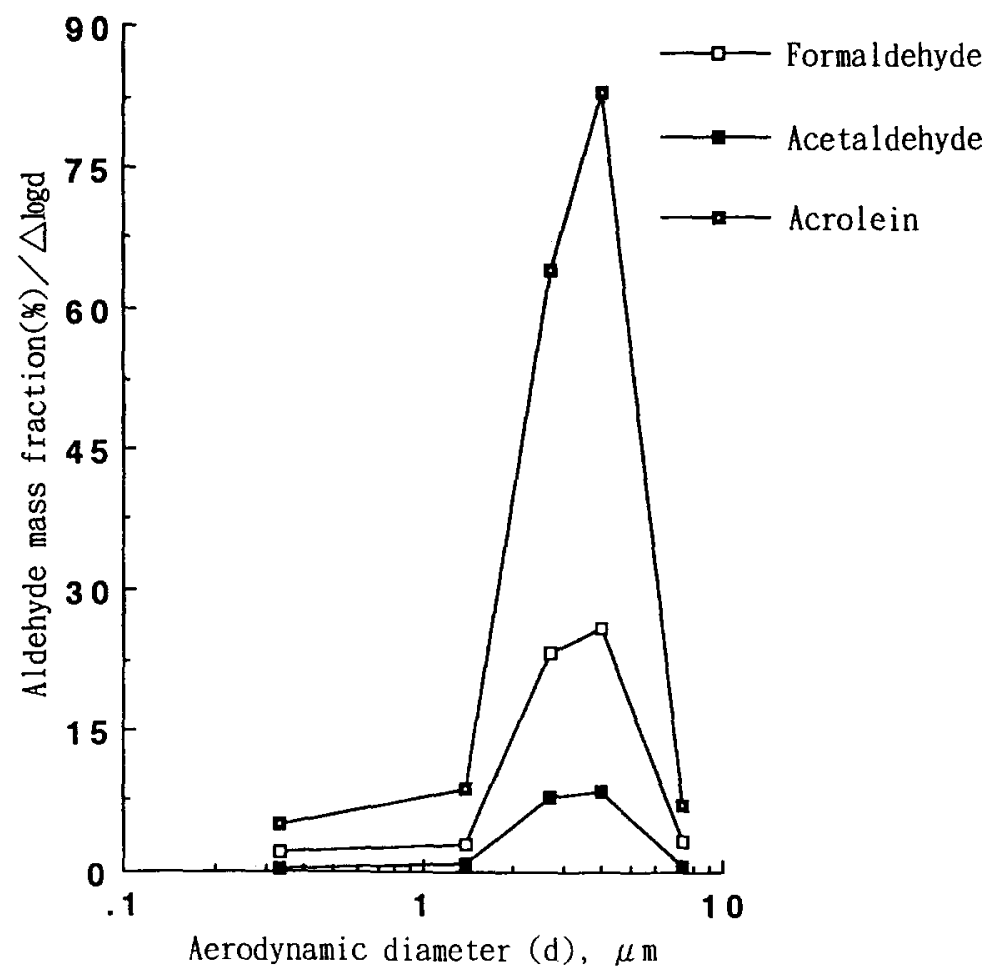

Figure 2. Mass distribution of aliphatic aldehydes on the particulates collected in a Chinese temple. (Aldehyde mass fraction indicates the mass percentage of each aldehyde versus the integral mass for that stated size range.)

However, as shown in Figure 1, the field data from a Chinese temple where Chinese incenses were burning in ambient air results in a linear plot with MMAD of $2.5 \mu \mathrm{m}$ on $\log$-probability paper.

Figure 2 shows that the quantity of various aliphatic aldehydes found in particulates was dependent on particle size in the field sample collected from the Chinese temple. Aerolein, formaldehyde and acetaldehyde were predominantly adsorped on particulates, especially those with size of 3.3-4.7 $\mu \mathrm{m}$ and $2.1-3.3 \mu \mathrm{m}$.

Table 3 shows that when particulates were generated from burning the incense stick in the previously described chamber, the relationship between aldehyde mass fraction and size of particle varied with the type of incense stick. The abundance of alphatic aldehydes adsorbed on particulates consistently kept the following order: acrolein, formaldehyde, acetaldehyde. A difference between aliphatic aldehydes on particulates and in the gaseous phase was noticed. It was found that formaldehyde predominated in the gaseous phase when an incense stick was burning in the chamber. (Lin and Mang, 1994, in press). 


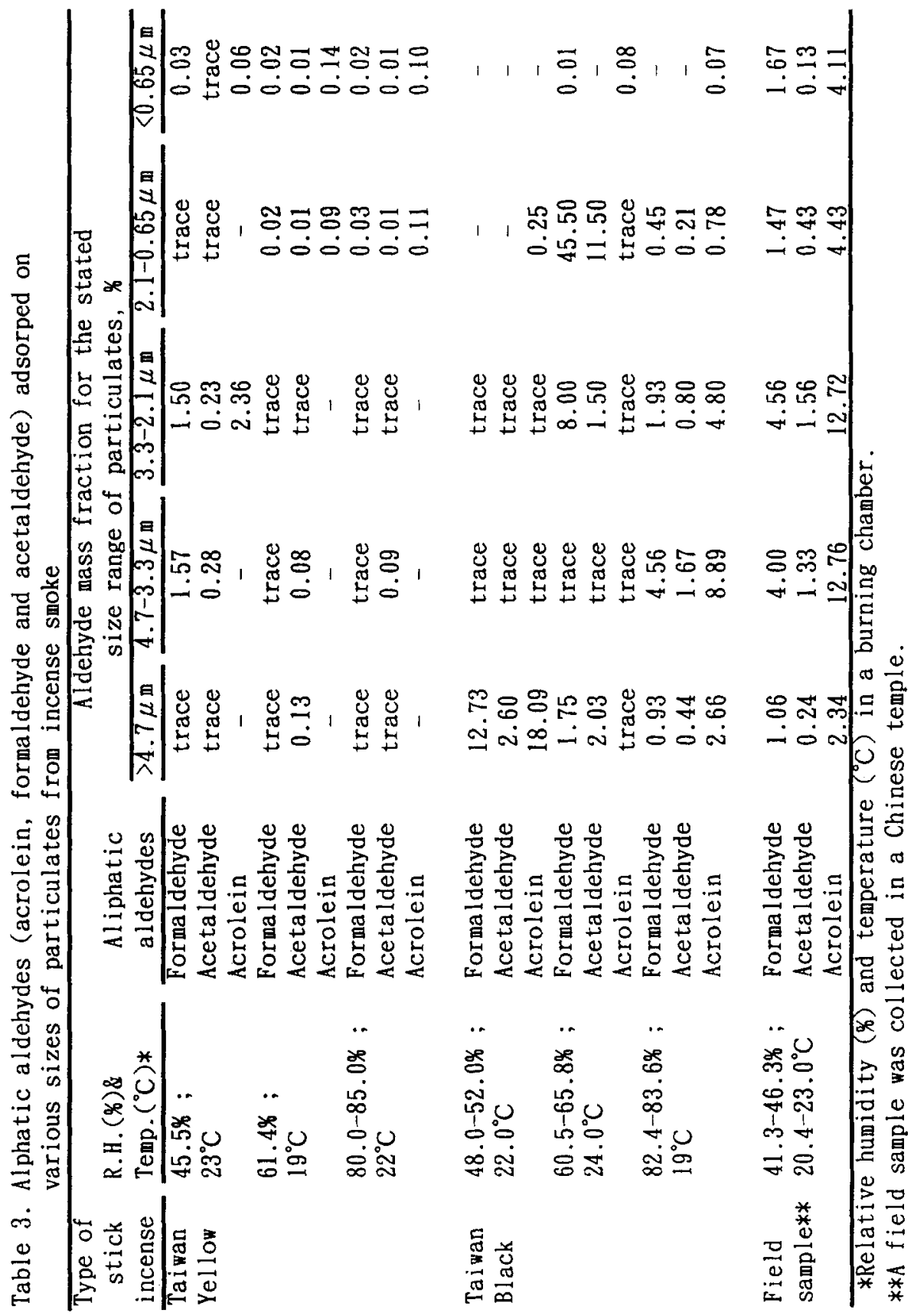


Acknowledgments. This study was supported by the National Science Council of the Republic of China, grant No. NSC-82-0412-B002-270. We thank Dr. Hui-Po Wang of National Taiwan University for her technical advice in HPLC, and Professor Kuo-Shen Lu of National Taiwan University for his generosity in allowing us to perform an electron microscopic scan.

\section{REFERENCES}

Black A, Evans JC, Hadfield EH, Macbeth RG, Morgan A, Walsh M (1974) Impairment of nasal mucociliary clearance in woodworkers in the furniture industry. Brit J Ind Med 31:10-17

Gotze HJ, Harke S (1989) Determination of aldehydes and ketones in natural gas combustion in the ppb range by HPLC. Fresenius $Z$ Anal Chem 335:286-288

Lin JM, Mang LH (1994) Gaseous aliphatic aldehydes in Chinese incense smoke. Bull Environ Contam Toxicol(in press).

National Research Council, Committees on Aldehydes, Board of Toxicology and Environmental Health Hazards, Assembly of Life Sciences (1981) Formaldehyde and other aldehydes. National Academy of Science Press, Mashington, DC, p 175-195

Stumph JM, Blehm KD, Buchan RM and Gunter BJ (1986) Characterization of particleboard aerosol - Size distribution and formaldehyde content. Am Ind Hyg Assoc J 47:725-730

Whitehead LT (1982) Health effects of wood dust-relevance for an occupational standard. Am Ind Hyg Assoc J 43:674-678 